\title{
Constitutive expression of pathogen-inducible OsWRKY31 enhances disease resistance and affects root growth and auxin response in transgenic rice plants
}

\author{
Juan Zhang ${ }^{1}$, Youliang Peng ${ }^{1}$, Zejian Guo ${ }^{1}$ \\ ${ }^{1}$ State Key Laboratory of Agrobiotechnology, Department of Plant Pathology, China Agricultural University, Yuanmingyuan West \\ Road 2, Beijing 100094, China
}

\begin{abstract}
WRKY transcription factors have many regulatory roles in response to biotic and abiotic stresses. In this study, we isolated a rice $W R K Y$ gene (OsWRKY31) that is induced by the rice blast fungus Magnaporthe grisea and auxin. This gene encodes a polypeptide of 211 amino-acid residues and belongs to a subgroup of the rice $W R K Y$ gene family that probably originated after the divergence of monocot and dicot plants. OsWRKY31 was found to be localized to the nucleus of onion epidermis cells to transiently express OsWRKY31-eGFP fusion protein. Analysis of OsWRKY31 and its mutants fused with a Gal4 DNA-binding domain indicated that OsWRKY31 has transactivation activity in yeast. Overexpression of the OsWRKY31 gene was found to enhance resistance against infection with $M$. grisea, and the transgenic lines exhibited reduced lateral root formation and elongation compared with wild-type and RNAi plants. The lines with overexpression showed constitutive expression of many defense-related genes, such as $P B Z 1$ and $O_{s} S c i 2$, as well as early auxin-response genes, such as $O_{s} I A A 4$ and $O s C r l 1$ genes. Furthermore, the plants with overexpression were less sensitive to exogenously supplied IBA, NAA and 2,4-D at high concentrations, suggesting that overexpression of the $O s W R K Y 31$ gene might alter the auxin response or transport. These results also suggest that OsWRKY31 might be a common component in the signal transduction pathways of the auxin response and the defense response in rice.
\end{abstract}

Keywords: WRKY transcription factor, Oryza sativa, defense response, lateral root

Cell Research (2008) 18:508-521. doi: 10.1038/cr.2007.104; published 11 December 2007

\section{Introduction}

Plants have evolved elaborate mechanisms to defend against pathogen invasion. Upon pathogen recognition, host cells undergo various biochemical and structural changes, such as burst of active oxygen species, hypersensitive response, accumulation of antimicrobial proteins and phytoalexins, deposition of callose papillae, and formation of cork and abscission layers [1]. The transcriptional activation of a large number of genes upon perception of external stimuli, including pathogenic infections, has often been demonstrated. Some of the ac-

Correspondence: Zejian Guo

Tel: +86-10-62733849

E-mail: guozj@cau.edu.cn

Received 12 February 2007; revised 15 June 2007; accepted 18 October 2007; published online 11 December 2007 tivated genes encode proteins that have regulatory functions, such as kinases and transcriptional factors, which may have important roles in signaling cascades [2].

Many reports indicate that plant mutants with enhanced disease resistance are usually small in size [3]. A possible explanation for the dwarf phenotype could lie in changes in the metabolic activities towards defense-related pathways, thus leading to the expression of defense genes and the accumulation of antimicrobial products against pathogens $[4,5]$. However, detailed knowledge about the pathway interactions between plant disease resistance and growth or development is still limited. Recently, SGT1b, first identified in yeast, was found to be a factor involved in plant disease resistance signaling and a factor necessary for the $\mathrm{SCF}^{\mathrm{TIR} 1}$ (SKP1-CDC53/ CUL1-F-box)-mediated degradation of auxin/indoleacetic acid (Aux/IAA) proteins [6-8]. The Arabidopsis sgt1b-1 mutant exhibits a reduction in the lateral root 
development in comparison with wild-type seedlings [8]. Loss of $S G T 1$ function disables the early plant defense mechanisms conferred by multiple $R$ gene-mediated and non-host pathogen resistance, showing the positive effect of auxin on disease resistance at an early stage [7,9]. However, some researches have found that in other conditions, auxin also has a role in disease susceptibility. For example, Navarro et al. [10] have demonstrated that a flagellin-derived peptide induces a plant microRNA that represses auxin signaling and leads to the restriction of Pseudomonas syringae growth in Arabidopsis. These results suggest that, for different pathogens or in different infection stages, crosstalk between the defense signaling and auxin response pathways is varied and complicated.

Auxin regulates the formation of lateral branches in roots and shoots, and regulates other aspects of plant growth and development [11]. Aux/IAA genes are rapidly upregulated in response to auxin [12]. Aux/IAA proteins, which are negative regulators of auxin signaling, regulate gene expression by interacting with auxin response factors (ARFs), which function as positive regulators by binding to AREs within the promoters of auxin-inducible genes $[12,13]$. Mutants that are deficient in auxin transport or insensitive to auxin have been reported to have a reduced number of lateral roots in both Arabidopsis [14, 15] and rice [16-18]. For example, a rice mutation in crll (crown rootless 1 ) decreases lateral root numbers and auxin insensitivity occurs during lateral root formation. Crll encodes a positive regulator for crown and lateral root formation and its expression is directly regulated by an ARF in the auxin signaling pathway [16]. The loss-offunction mutants of $A R F 3, A R F 5$ and $A R F 7$ also exhibit reduced sensitivity to auxin, which results in defects in specific auxin-dependent phenomena, such as the formation of the gynoecium, the development of the vascular system and the differential growth responses of hypocotyls [19-22]. Whereas overexpressing ARF8 in Arabidopsis represses the growth of lateral roots, ARF8 may control free IAA levels in a negative feedback fashion by regulating the expression of $G H 3$ genes, which may be involved in maintaining IAA homeostasis $[22,23]$. These results indicate that $A R F$ family genes may have a central role in auxin-triggered responses by regulating both auxin sensitivity and homeostasis in Arabidopsis. However, it is imperative to identify the mediators that link the control of Aux/IAAs by auxin to root formation and elongation.

Many WRKY proteins have been found to be involved in defense against pathogenic attack in Arabidopsis, tobacco and parsley [24-29]. In rice, OsiWRKY and OsWRKY52 were induced by Xanthomonas oryzae pv. oryzae and Magnaporthe grisea, respectively [30, 31], and
OsWRKY03 was shown to be a transcriptional activator in defense signaling cascades [32]. Furthermore, WRKY proteins have been shown to have roles in developmental and physiological processes, such as in senescence [33], metabolism [34-36], trichome development [37] and root development [38]. In this study, we report that $O s$ WRKY31 (named as WRKY55 by Xie et al. [35]), a rice $W R K Y$ transcription factor gene, was strongly induced by the rice blast fungus $M$. grisea and auxin. Further analyses indicate that OsWRKY31 may be a common component in the signal transduction pathways of auxin and defense responses in rice.

\section{Results}

\section{Cloning of the OsWRKY31 gene and sequence analysis}

From a rice (IR72) cDNA library generated with elicitor-treated rice suspension cells, the OsWRKY31 gene was amplified with gene-specific primers designed according to the deposited genomic sequence and the expressed sequence tags (GenBank acc. no: AK101653). The open reading frame was $633 \mathrm{bp}$ in length, encoding a protein of 211 amino-acid residues with a molecular weight of $24.0 \mathrm{kDa}$ and a $p I$ of 7.35 . There was one nucleotide change from $\mathrm{T}$ in Nipponbare to $\mathrm{C}$ in IR72, leading to an amino-acid change of Ser to Pro at position 116 of the encoded protein. The putative protein harbors two regions that are rich in Ser (aa 120-137) and acidic amino acids (aa 181-197) in the C-terminal of OsWRKY31, which suggests that they may be involved in transcriptional activation (Figure 1). Besides a putative nuclear localization signal (NLS) sequence RKEKRMRK, OsWRKY31 has only one WRKY domain that contains an extended finger motif of $\mathrm{CX}_{7} \mathrm{CX}_{27} \mathrm{HX}_{1} \mathrm{C}$, compared with the typical WRKY domain $\left(\mathrm{CX}_{7} \mathrm{CX}_{23} \mathrm{HX}_{1} \mathrm{C}\right)$ from other species $[39,40]$. A phylogenetic tree generated with OsWRKY31, and several closely related WRKY proteins from different plant species based on BLAST analyses, showed that OsWRKY31 clusters only with rice WRKYs of the same subgroup (data not shown). This result agrees with those obtained previously and indicates that OsWRKY31 belongs to the rice IIIb subgroup and was possibly generated after the divergence of monocot and dicot plants [40]. The extended zinc-finger motif in OsWRKY31 may also reflect the different divergent force for this family of genes between rice and Arabidopsis. There is also a change of Q to E in OsWRKY31 within the conserved septimal WRKYGQK residues of WRKY proteins.

\section{Nuclear localization of OsWRKY31}

Sequence analysis showed that OsWRKY31 contains 

1 AT t g gatcct cct tct ct ct ct ggaaaca

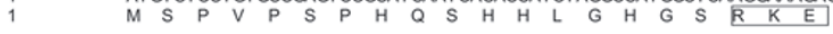
61 AAGCGCATGAGGAAGTGGATACCTTT GCGCOGCACAACGACGGCCACCAGT GGAGGAAG 21 K R M R K V D T F A P H N D G H Q W R K 121 TACGGCGAGAGAAGATAAACAACTGTAATTTCCCCAGATACTACTACAGATGCACCTAT

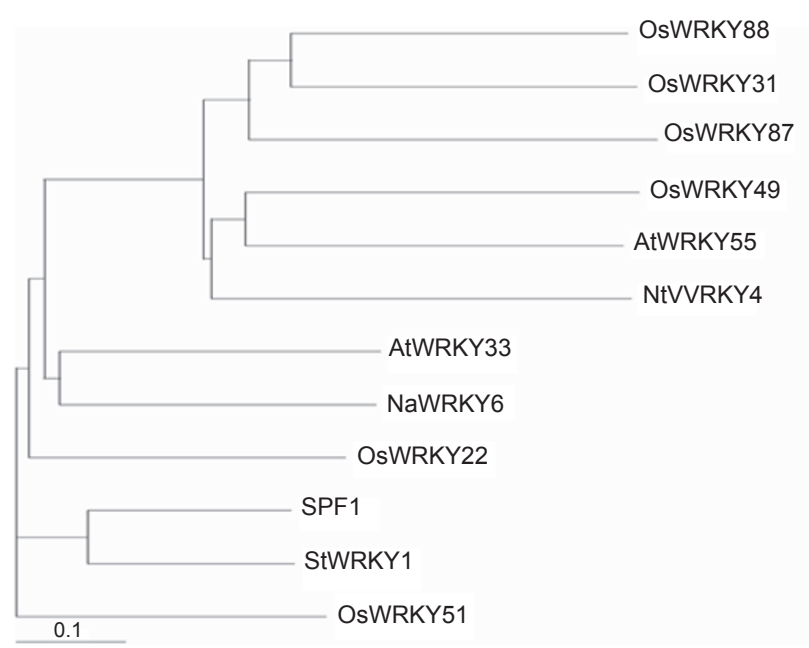

Figure 1 OsWRKY31 sequences and phylogenetic analysis. (A) The nucleotide sequence of OsWRKY31 cDNA and its deduced amino-acid sequence. The $5^{\prime}$-untranslated region is italicized. The residues forming the WRKY domain are in bold and shaded, including the conserved amino-acid residues. Cysteine and histidine residues making up the potential zinc-finger motif are underlined. The putative nuclear localization signals are boxed. The asterisk indicates the stop codon. The acidic residues underlined suggest a potential transactivation region. (B) The phylogenetic tree of OsWRKY31 with close homologs from a BLAST search. The deduced amino-acid sequence of OsWRKY31 was aligned with some of the published members of WRKY using the CLUSTAL W program and the phylogenetic tree was drawn using the TREEVIEW program to produce a neighbor-joining tree of the full-length amino-acid sequences from WRKY proteins. The GenBank accession numbers are listed in brackets for each of the following WRKY proteins: OsWRKY88 (AK073243), OsWRKY87 (AC123514), OsWRKY49 (AC136227), AtWRKY55 (AAY78725), NtWRKY4 (AAF61864), AtWRKY33 (AAM34736), NaWRKY6 (AAS13440), OsWRKY22 (AK107199), SPF1 (BAA06278), StWRKY1 (BAE46417) and OsWRKY51 (AK121190). a putative NLS and may be a nuclear factor in rice cells. To examine this possibility, the OsWRKY31 gene was fused in frame with a fluorescent reporter $g f p$ gene. The chimeric gene was put under the control of a CaMV35S promoter (pCaMV35S::OsWRKY31-eGFP) and then bombarded into inner epidermal onion cells. After cultivation in the dark at $28{ }^{\circ} \mathrm{C}$ for $18 \mathrm{~h}$, fluorescence was observed under a laser confocal microscope. As shown in Figure 2, the OsWRKY31-eGFP fusion protein was exclusively localized in the nucleus, whereas the control eGFP (pCaMV35S::eGFP) had spread into the cytoplasm as well as into the nucleus. This result reveals that OsWRKY31 is a nuclear protein.

\section{OsWRKY31 has transactivation activity in yeast}

All transformants harboring OsWRKY31 or its deletion mutants grew well on the synthetic SD-Trp medium (Figure 3A) and pBD-W31 grew normally on the SDTrp-His-Ade medium. Deletion of the $61 \mathrm{C}$-terminal amino acids (pBD-C1) decreased $\beta$-galactosidase activity of pBD-W31 by half, and pBD-dC1 exhibited transactivation activity (Figure 3B). Further deletion of the putative acidic region (pBD-C2) abolished the transactivation activity.

However, pBD-N1 produced only $38.4 \%$ of the activity produced by $\mathrm{pBD}-\mathrm{W} 31$. To clarify the possible effect of the 93 N-terminal regions, we generated several plasmids with different deletions of the $\mathrm{N}$-terminal amino acids based on the $\mathrm{pBD}-\mathrm{C} 1$ construct. The $\mathrm{pBD}-\mathrm{N} 3,-\mathrm{N} 4$ and -N5 mutants almost completely lost $\beta$-galactosidase activity (Figure $3 \mathrm{~B}$ ), which indicates that the entire $\mathrm{N}$-terminal region is required for transcription activity. Alternatively, the WRKY domain could suppress tran-
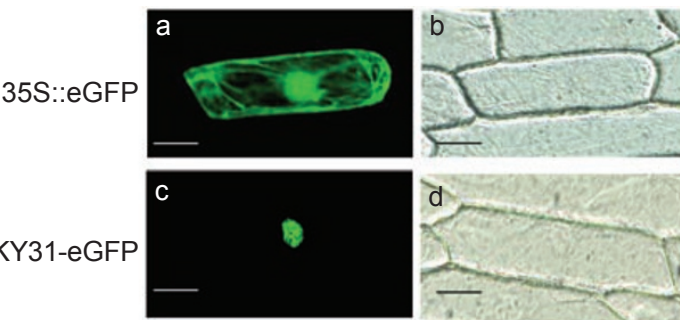

Figure 2 Localization of the OsWRKY31-eGFP fusion protein in the nucleus. The OsWRKY31-eGFP fusion protein was localized in the nucleus using a transient expression assay in onion. The control 35S::eGFP and 35S::OsWRKY31-eGFP plasmids were transformed into onion epidermal cells and examined after $18 \mathrm{~h}$. GFP fluorescence (left panel) and differential contrast imagery (right panel) were compared to show the subcellular localization of eGFP (cytoplasmic and nuclear) and OsWRKY31-eGFP (nuclear). Scale bars indicate $100 \mu \mathrm{m}$. 
A
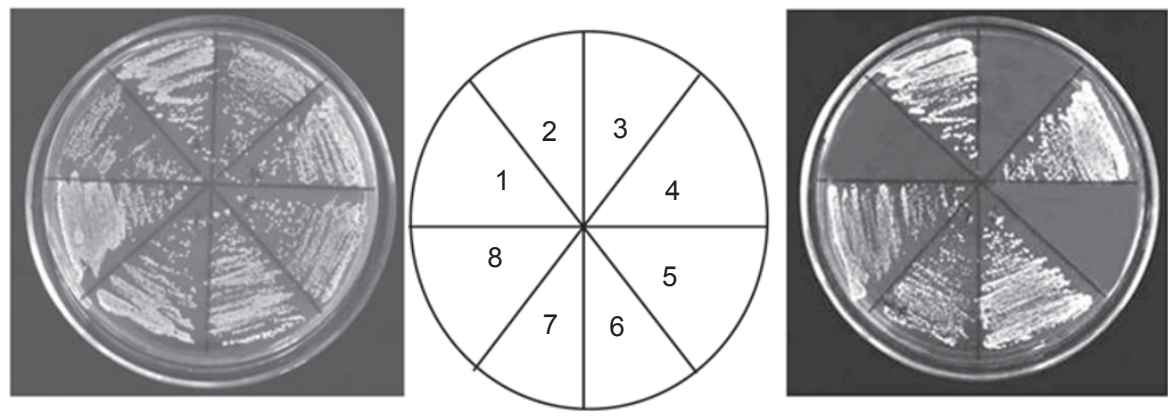

B

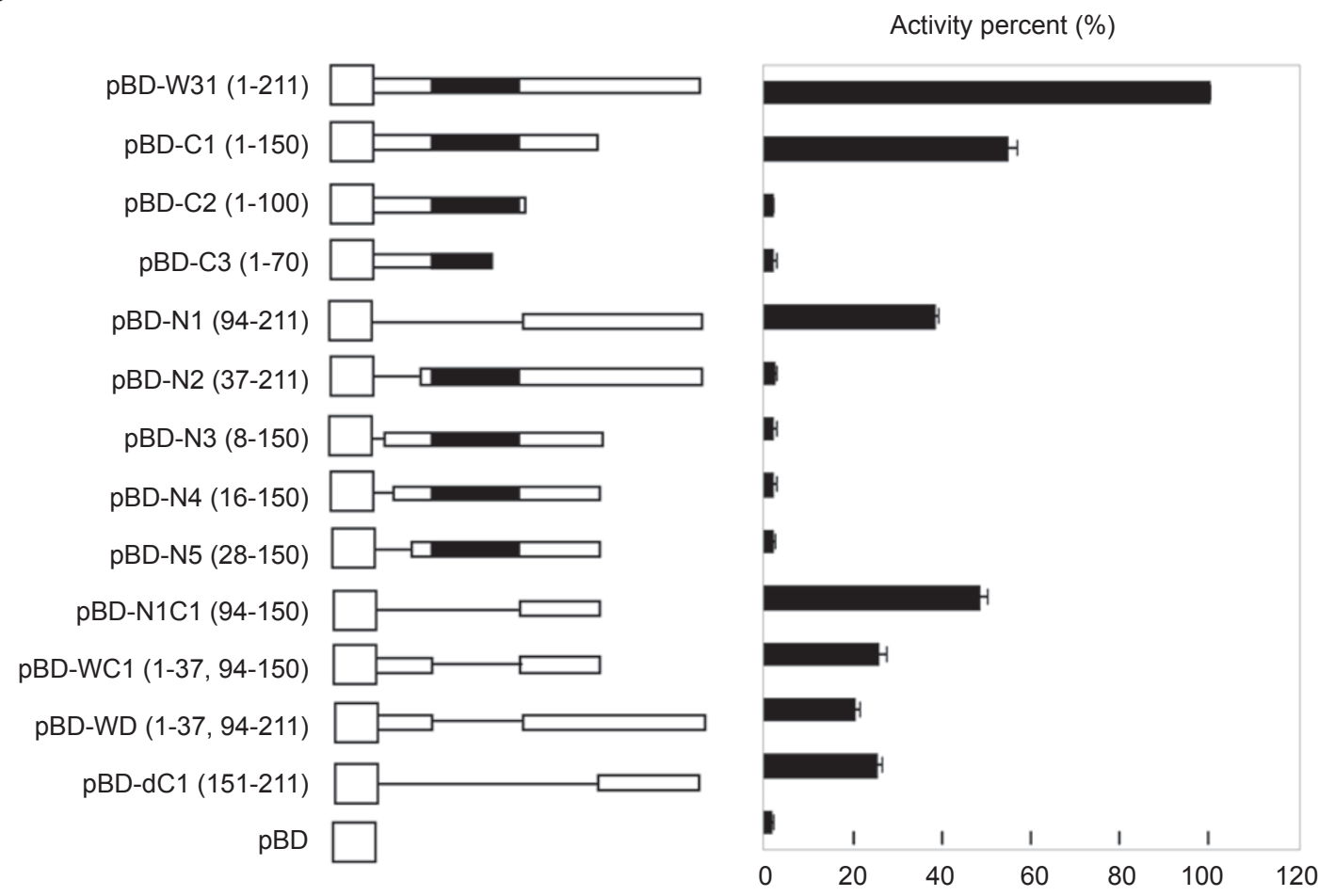

Figure 3 Analysis of the OsWRKY31 transactivation activity and activation domain in yeast. (A) The constructed vectors were transformed into the AH109 strain of yeast, and were grown on SD-Trp medium (left) and SD-Trp-Ade-His selective medium (right) at $30{ }^{\circ} \mathrm{C}$ for 3 days. 1, pBD; 2, pBD-W31; 3, pBD-C2; 4, pBD-C1; 5, pBD-N2; 6, pBD-N1; 7, pBD-N1C1; 8, pBD-WD. (B) $\beta$-galactosidase activity of transformants was assayed using $O$-nitrophenyl $\beta$-D-galatopyranoside as a substrate. The values from three independent experiments were shown as the mean \pm SE. The white square represents $p B D$ in pGBKT7, the black rectangle represents the WRKY domain of OsWRKY31, the white rectangle represents the rest of OsWRKY31 and the line represents the deleted part. The numbers in brackets are the start and end positions of each translated product of OsWRKY31 in the construct.

scription activity when the $\mathrm{N}$-terminus is incomplete, which is supported by evidence from the pBD-N1C1 and pBD-N2 transformants. But the deletion of the WRKY domain region (pBD-WD and $\mathrm{pBD}-\mathrm{WC} 1$ ) did not increase transactivation activity in comparison with their parent plasmids pBD-W31 and pBD-C1. These findings suggest that OsWRKY31 is a transcriptional activator in yeast at least. The active regions were found to be the Ser-rich and the acidic amino-acid-rich $\mathrm{C}$-terminal regions. The region of the WRKY domain might have a repressive role, in which the effect could be counteracted by the presence of the $\mathrm{N}$-terminal region.

\section{OsWRKY31 expression was induced by pathogens and wounding}

In a preliminary microarray study on the expression patterns of rice WRKY genes, we found that OsWRKY31 expression was induced by the M. grisea pathogen (Guo 
et al., unpublished results). To learn its more detailed expression profile, OsWRKY31 expression was examined in the rice cultivar Zhonghua17 under different treatments. As shown in Figure 4, the mRNA accumulation of the OsWRKY31 gene was induced as early as $4 \mathrm{~h}$ after inoculation with an avirulent strain (P131) of M. grisea, and lasted throughout the period studied. Induction of the OsWRKY31 gene was also observed following infection with a compatible strain MS220, although the expression level was lower than that of P131 at the same time point (Figure 4). To examine the quality of pathogenic inoculation, the same blot was striped and re-hybridized with an $\mathrm{OsSCi2}$ gene belonging to the subtilisin chymotrypsin inhibitor gene family, which is strongly induced by $M$. grisea (Zhao and Peng, personal communication). Induction of OsSci2 by the P131 and MS220 strains in Zhonghua17 revealed that the expression of OsWRKY31 is the consequence of pathogenic infection.

Analysis of this gene's expression was extended to mechanical wounding and methyl jasmonate (MeJA), an important signal molecule in plant defense responses. The accumulation of OsWRKY31 mRNA occurred soon after wounding, with the mRNA levels increasing during the later time points (Figure 4). OsWRKY31 gene expression was also stimulated by treatment with MeJA (Figure 4 ), although the induced response was relatively slow in comparison with the responses induced by pathogens or wounding.
OsWRKY31 overexpression enhances resistance to $M$. grisea and induces expression of defense-related genes

Transgenic rice plants were generated to explore the possible biological functions of OsWRKY31; 18 overexpression lines and 16 RNAi lines were obtained using an Agrobacterium-mediated methodology and were allowed to set seeds. Some of the $T_{1}$ progeny lines were then randomly selected to determine the expression of the transgene. As shown in Figure 5A, constitutive expression of the OsWRKY31 gene was observed in the overexpression lines, whereas expression of the gene was not detected in the control or RNAi lines.

To examine whether OsWRKY31 overexpression enhances disease resistance, transgenic and control plants were inoculated with a strong virulent strain of $M$. grisea (P140) by spraying. The development of disease was noticeably less in the OsWRKY31 overexpressing progenies compared with control and RNAi lines (Figure 5B). Disease incidence was evaluated 1 week after inoculation by measuring the number and size of lesions. The results revealed a significant decrease in both occurrence and symptom development in the OsWRKY31 overexpression lines compared with the control (Figure 5C and 5D). However, the level of disease found in the RNAi lines was similar to the control (data not shown). Analysis of mRNA accumulation by northern blotting revealed that the expression of $O s W R K Y 31$ was suppressed in the RNAi lines even after inoculation with the pathogen

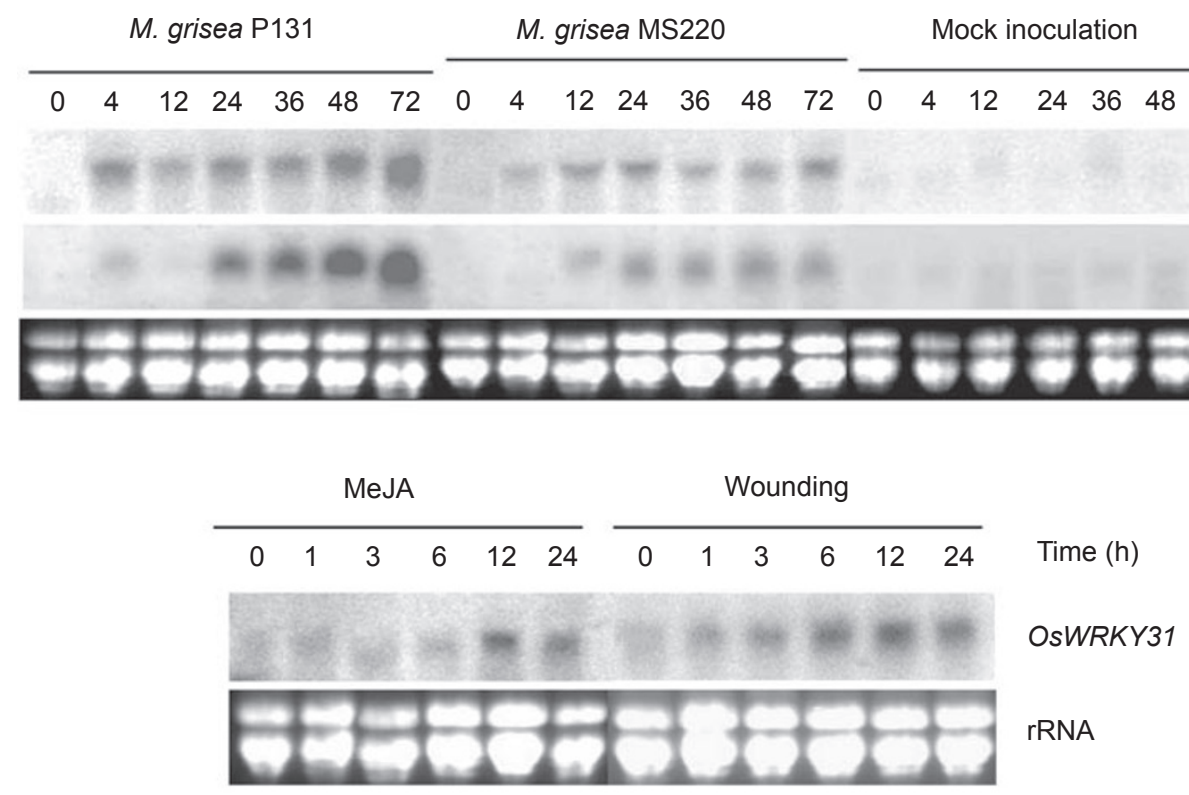

Figure 4 OsWRKY31 expression is induced by biotic and abiotic stresses. Total RNA was isolated from the leaves of rice seedlings at different time points. An equal loading of $20 \mu \mathrm{g}$ RNA to each lane was checked using ethidium bromide staining. ${ }^{32} \mathrm{P}$-labeled OsWRKY31 and OsSci2 were used as probes for hybridization. 
A

$\begin{array}{llllllllllllllllllllll}\text { Zh } & \text { S2 } & \text { S7 } & \text { S8 } & \text { S21 } & \text { S19 S22 } & \text { S23 } & \text { D7 } & \text { D14 } & \text { D16 } & \text { D20 } & \text { D26 } & \text { D30 } & \text { D31 } & \text { D37 }\end{array}$

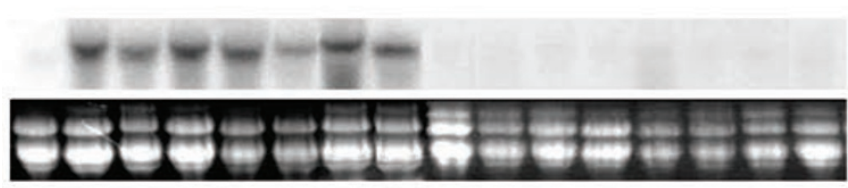

B

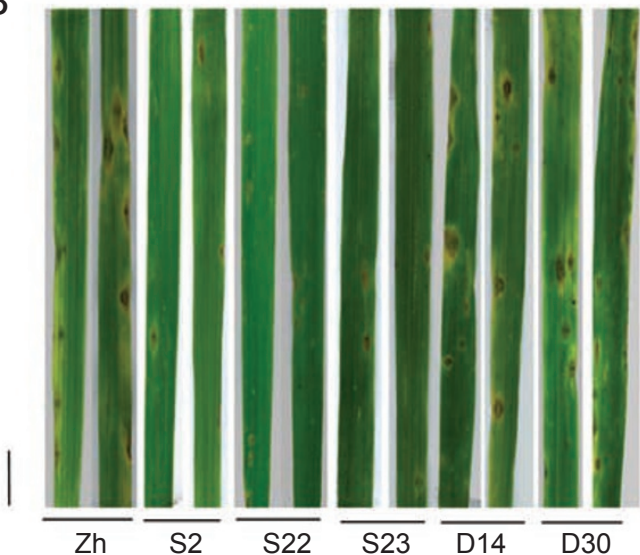

C

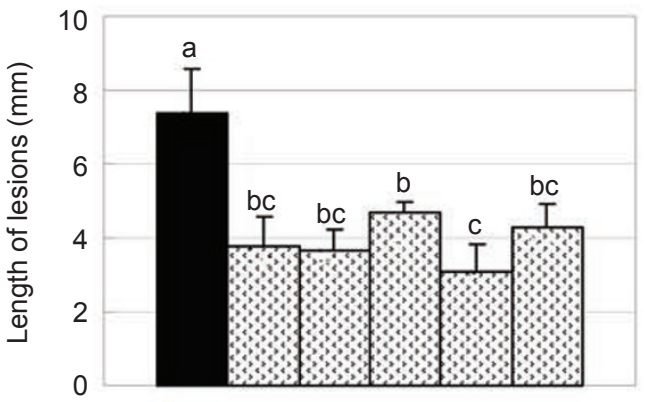

OsWRKY31 rRNA

D

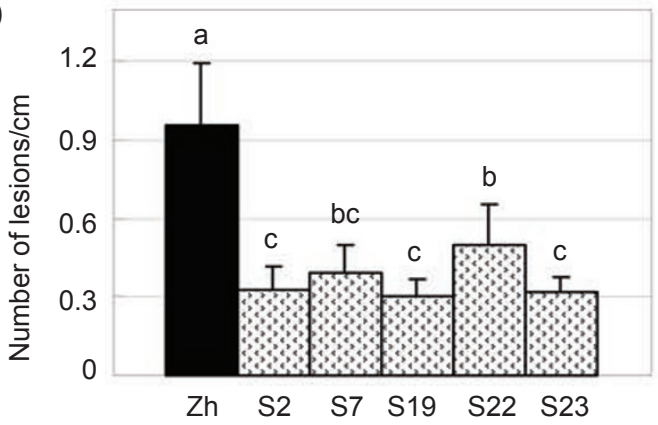

$E$

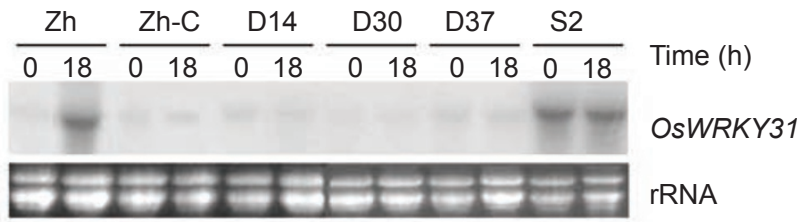

$\mathrm{F}$

PBZ1 (27)

OsSci2 (27)

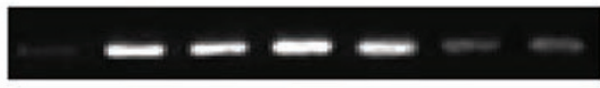

OsWRKY31 (26)

OsActin (25)

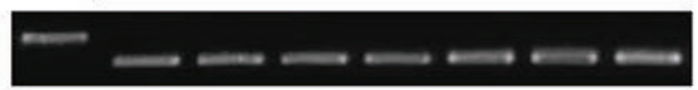

$\begin{array}{lllllllll}\text { gene (cycles) } & \text { gDNA } & \text { Zh } & \text { S2 } & \text { S7 } & \text { S8 } & \text { S23 } & \text { D14 } & \text { D30 }\end{array}$

Figure 5 OsWRKY31 overexpression enhances disease resistance and induces expression of defense-related genes. (A) OsWRKY31 expression in the overexpression (S), RNAi (D) and control (Zh) plants. An equal loading of $15 \mu \mathrm{g}$ RA to each lane was checked using ethidium bromide staining. ${ }^{32} \mathrm{P}$-labeled OsWRKY31 was used for hybridization. The numbers indicate the different transgenic lines. (B) Three-week-old transgenic rice seedlings were inoculated with a virulent strain of $M$. grisea P140. Leaves were detached from the inoculated plants 5 days after the infection and then scanned. (C and D) Histograms showing the lesion length (C) and number (D). The disease incidence was evaluated 7 days post-inoculation. Each bar indicates the average and standard deviation of at least five leaves. Different letters $(a, b$ and $c)$ indicate statistically significant differences as analyzed by the SAS software (Duncan's multiple range test; $\alpha=0.01$ ). (E) OsWRKY31 transcription in RNAi lines (D14, D30 and D37), control plants (Zh and Zh-C), and overexpression line (S2) after inoculation or mock inoculation (Zh-C) with M. grisea P140 for 18 h. (F) Gene expression was determined by semiquantitative RT-PCR. The RNAs from the overexpression (S2, S7, S8, S23), RNAi (D14, D30) and control (Zh) plants were reverse-transcribed and used as templates for PCR. The actin gene was used as an internal standard and also amplified using genomic DNA (gDNA) as a template to check the gDNA contamination in the transcribed RNAs.

(Figure 5E).

To study whether the enhanced disease resistance was related to enhanced expression of defense-related genes, we selected four overexpression and two RNAi lines to detect mRNA levels using a semiquantitative RT-PCR method. Constitutive expression of OsWRKY31 was observed in the overexpression lines, whereas the accumulation of OsWRKY31 mRNA was low in the control and RNAi plants (Figure 5F). Similarly, we observed the constitutive expression of $P R$ genes, such as $O s S c i 2$ and $P B Z 1$, in the overexpressor transgenics, whereas these genes were expressed at much lower levels in the control 
and RNAi progenies, suggesting that the increase of disease resistance might be due to the constitutive expression of the defense genes in the OsWRKY31 overexpressing lines.

Ectopic expression of OsWRKY31 reduced the formation and elongation of lateral roots

When handling the rice seedlings, we noticed a difference in the formation of lateral roots between the OsWRKY31 overexpression and control lines. Therefore, we selected some of the transgenic lines for more detailed examination. Seeds of the transgenic plants of the $T_{2}$ progeny were germinated and grown on a $1 / 2 \mathrm{MS}$ medium with $0.6 \%$ agar. Evaluation of 7-day-old rice seedlings revealed that the number of lateral roots was significantly less in the OsWRKY31 overexpressing lines than in the control plants (Figure 6A-F). The length of the lateral roots was also shorter in the overexpressor progenies in comparison with the control plants. Furthermore, 10 out of 18 of the overexpressor lines still exhibited dwarfism and fewer roots in comparison with the control plants at the heading stage (Figure 6G and $6 \mathrm{H}$ ), which exhibited noticeably reduced lateral root formation and elongation in seed roots and crown roots (Figure 6I). A similar examination was performed on the seedlings harboring the hairpin construct; however, the difference

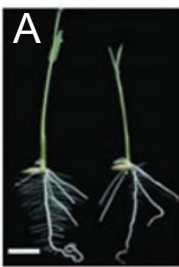

Zh S2

E

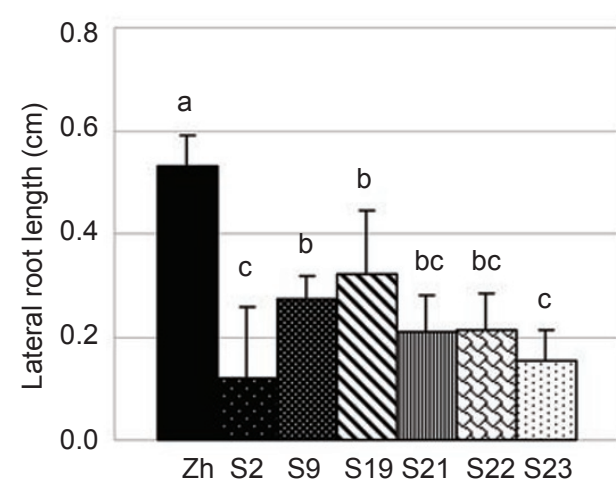

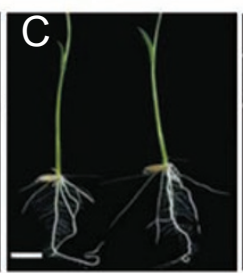

D14

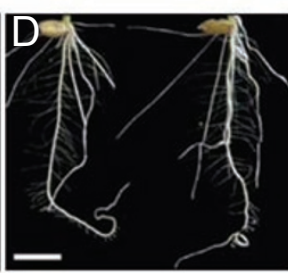

Zh

D14

$\mathrm{F}$

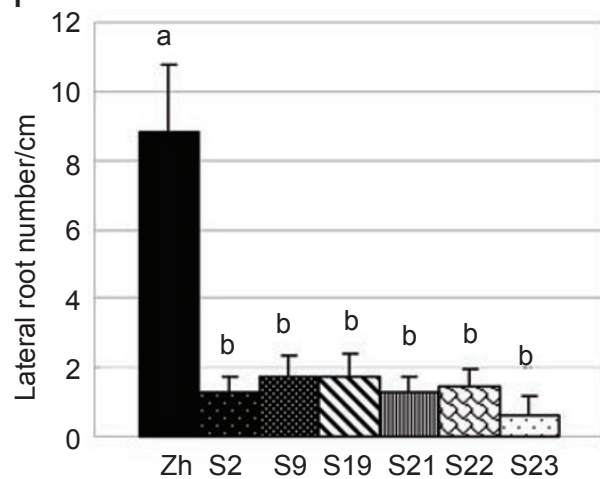

Zh S2 S9 S19 S21 S22 S23

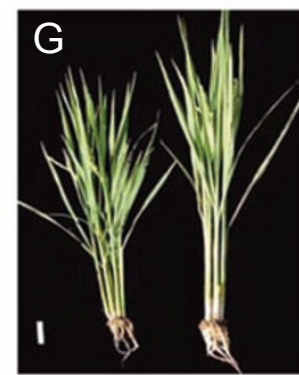

S2

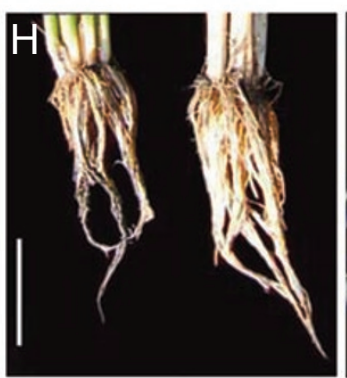

S2

Zh

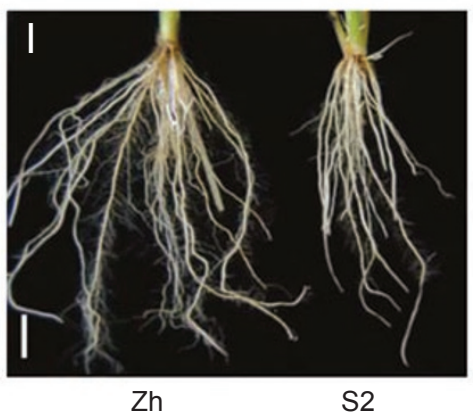

Zh

S2

Figure 6 Reduced lateral root formation and elongation by ectopic expression of OsWRKY31. (A-D) Overexpression plants showed a decrease in lateral root formation and elongation, whereas the RNAi line was not apparently different from the control plant. Pictures were taken from 7-day-old seedlings. (E and F) Histograms showing the changes in lateral root length (E) and number $(\mathbf{F})$ in overexpression plants compared with control plants. Figures represent the means \pm SD from at least 15 plants for each line. (G-I) Images showing the differences in plant height and the root formation between overexpression (S2) and control $(\mathrm{Zh})$ lines at their heading stage. Scale bars indicate $5 \mathrm{~cm}$ in $(\mathbf{H})$ and $1 \mathrm{~cm}$ in other parts. Different letters (a,b and c) indicate statistically significant differences as analyzed by the SAS software (Duncan's multiple range test; $\alpha=0.01$ ). 
A

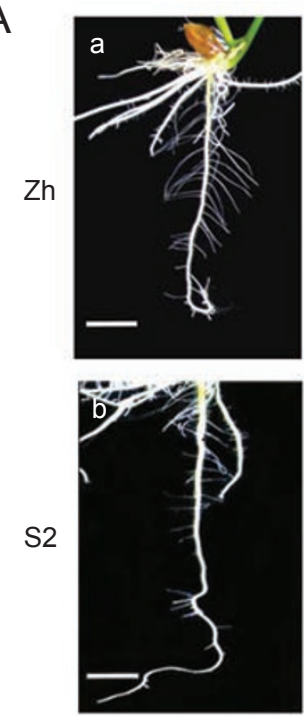

$\operatorname{IBA}(\mathrm{M})$

0
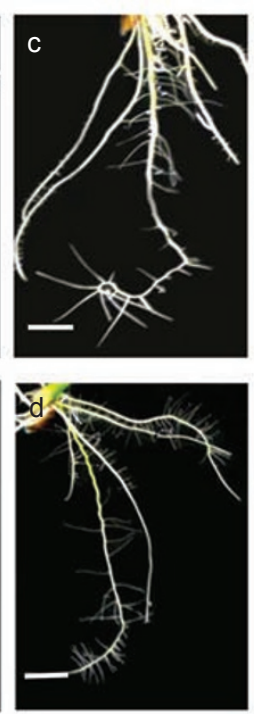

$10^{-8}$
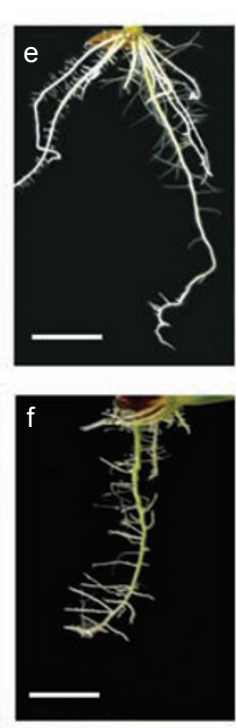

$10^{-6}$

E

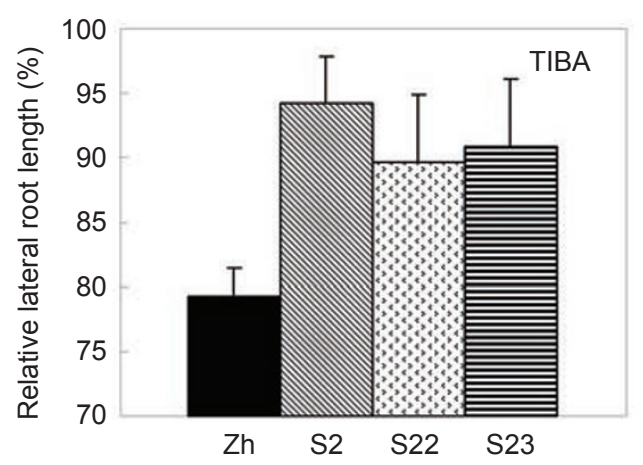

B

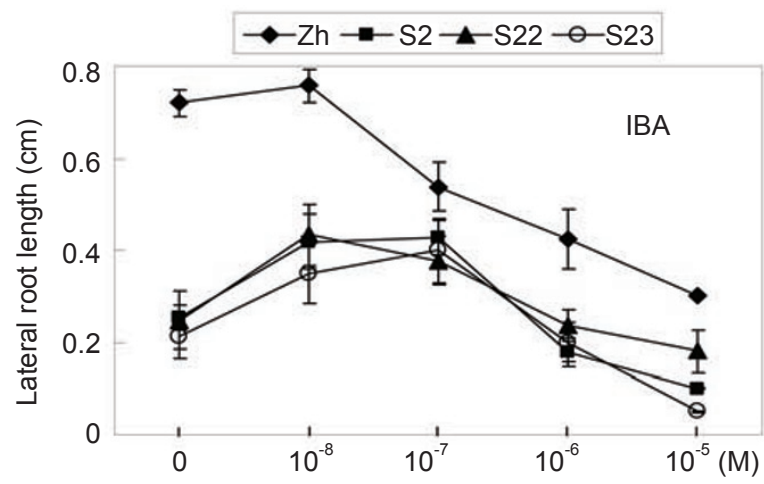

C

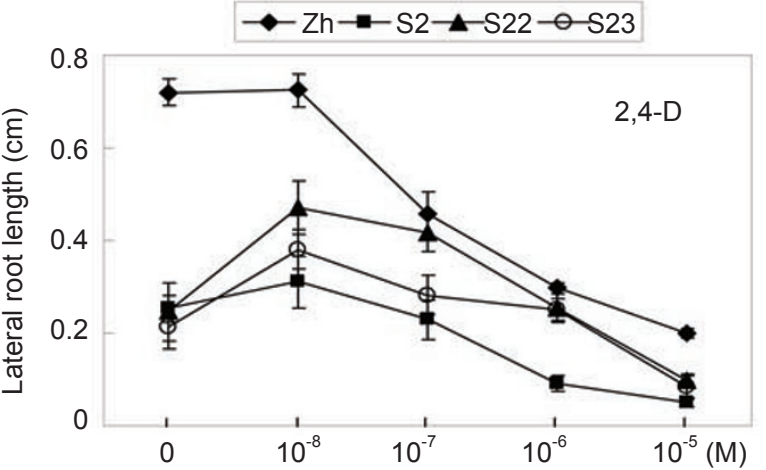

D

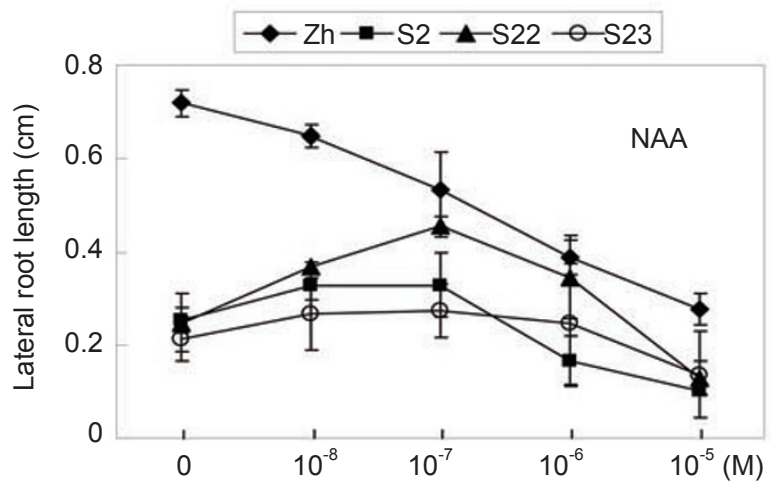

Figure 7 Effect of exogenous auxin on lateral root elongation. (A) The phenotypes of control (Zh: a, c and e) and overexpression lines (S2: b, $d$ and f) in lateral root elongation after treatment with $10^{-8} \mathrm{M}$ IBA (c, d), $10^{-6} \mathrm{M}$ IBA (e, f) or without IBA (a, b). (B-D) Plants were treated with different concentrations of IBA, NAA and 2,4-D. The lengths of lateral roots were measured 6 days after the auxin treatments. The means \pm SD of the 20 longest lateral roots are given for each line. (E) Plants were treated with $10^{-6} \mathrm{M}$ of TIBA or water. The relative lateral root length is given as a percentage of untreated plants against the control and overexpression lines. Scale bars indicate $1 \mathrm{~cm}$.

between the RNAi lines and the control plants was not statistically significant (data not shown).

Responses to exogenous auxin in the lateral root elongation of OsWRKY31 overexpressing plants

In general, the initiation and later development of lateral roots are related to auxin. Therefore, a doseresponse assay was conducted to examine the response of the transgenic plants to exogenous auxin. Both control and transgenic plants were treated with different types of auxin and the length of lateral root was determined according to the method described by Debi et al. [18]. Similarly, we observed that treatment with IBA promoted slight lateral root elongation at a lower concentration $\left(10^{-8} \mathrm{M}\right)$ and exhibited inhibitory effects at a higher concentration (up to $10^{-7} \mathrm{M}$ ) in the control plants (Figure $7 \mathrm{~A}$ and $7 \mathrm{~B})$. In the OsWRKY31 overexpressing lines, the length of lateral roots nearly doubled following treatment with IBA at $10^{-7} \mathrm{M}$ compared with non-treatment, and was inhibited when the concentration of IBA was $10^{-6}$ 
M. Similar phenomena were observed in the treatment of transgenic plants with NAA or 2,4-D (Figure 7C and 7D), although the response to the NAA treatment varied between individual transgenic lines. Furthermore, the effect of auxin transport inhibitors on root elongation was examined. The results indicate that the OsWRKY31 overexpressing lines exhibit slightly more resistance to the auxin transport inhibitor TIBA in comparison with the response of the control seedlings (Figure 7E).

\section{OsWRKY31 is an auxin inducible gene}

To examine whether OsWRKY31 is regulated by auxin, we investigated the expression of the OsWRKY31 gene following application of the hormone. As shown in Figure 8A, induction of OsWRKY31 was observed through the treatment of rice roots with IBA $(1 \mu \mathrm{M})$ and 1-NAA (an active form of auxin, $1 \mu \mathrm{M}$ ), whereas the accumulation of OsWRKY31 mRNA was not induced by treatment with the inactive 2-NAA $(1 \mu \mathrm{M})$. This suggests that $O s W R K Y 31$ is an auxin-inducible gene.

Moreover, the expression of OsWRKY31 at early time points was studied after the treatment of exogenous auxin using an RT-PCR method. Induction of OsWRKY31 in rice roots was observed as early as half an hour after the treatment with $1 \mu \mathrm{M}$ IBA and its level gradually increased with time (Figure $8 \mathrm{~B}$ ). To investigate the relationship of OsWRKY31 with other auxin-induced genes, we also determined the expression of OSIAA4, a member of the early auxin response $A u x / I A A$ gene family, and the OsCrll gene, an essential gene for crown root formation in rice [16]. The induction profiles for both genes, also described by Inukai et al. [16], were similar to the induction profile of OsWRKY31 (Figure 8B). Interestingly, constitutive expression of the OsIAA4 and $\mathrm{OsCrll}$ genes was observed in the OsWRKY31 overexpressor lines of $\mathrm{T}_{2}$ progenies and their expressions were not increased further by the treatment of the overexpressor plants with IBA (Figure 8C). These results suggest that OsWRKY3I may be involved in auxin signaling.

\section{Discussion}

The WRKY transcription factors have been shown to have important roles in biotic and abiotic stresses. However, most studies have focused on dicot plants such as Arabidopsis and tobacco, with only a few focusing on rice WRKYs. In a previous study, we phylogenetically classified the rice $W R K Y$ gene family and compared them with their counterparts in Arabidopsis [40]. In rice the genes in the IIIb subgroup are considered to have been generated sometime after the divergence of monocot and dicot plants, and possibly have a special role in
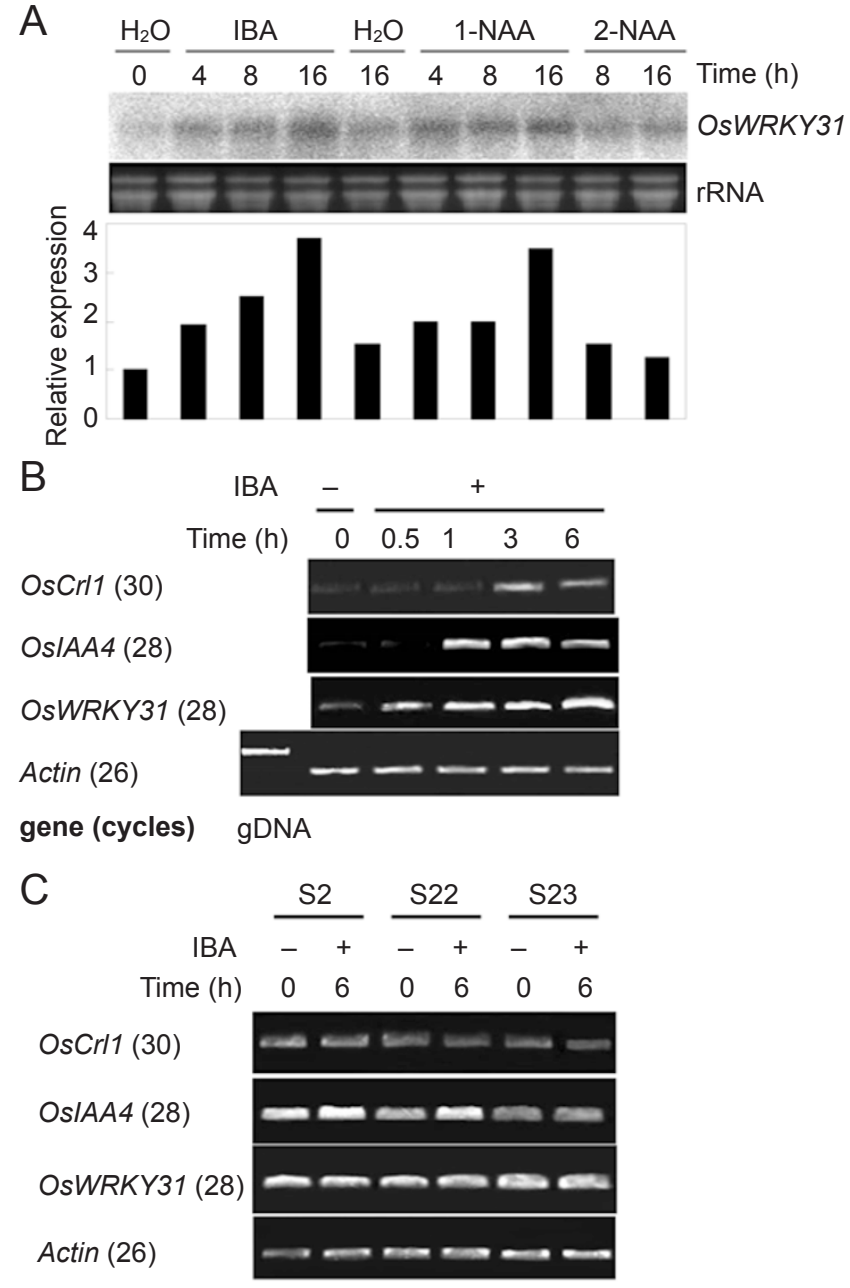

gene (cycles)

Figure 8 OsWRKY31 induction with auxin treatments and constitutive expression of the auxin-response genes in OsWRKY31 overexpressing lines. (A) OsWRKY31 expression was analyzed in rice roots that were treated with $1 \mu \mathrm{M}$ of $1-\mathrm{NAA}$, its inactive analog 2-NAA and IBA, using $\mathrm{H}_{2} \mathrm{O}$ as a control, at different time points. Relative levels are shown. (B and $\mathbf{C}$ ) Analyses of gene expression by semiquantitative RT-PCR. Four-day-old seedlings of the control (B) and overexpressing (C) plants were treated with or without $1 \mu \mathrm{M}$ IBA. The actin gene was used as an internal standard and was amplified using genomic DNA (gDNA) as a template to check the gDNA contamination in the transcribed RNAs.

rice plants. In this study, we have characterized the $O s$ WRKY31 gene, a member of rice IIIb subgroup.

OsWRKY31 contains regions that are rich in Ser and in acidic amino acids in its $\mathrm{C}$ terminus, which act as transcription activation domains in yeast (Figure 3). However, this activity seems to be affected by complicated factors. Deletion of several amino acids from the $\mathrm{N}$ terminus 
eliminates transcriptional activity, which is in contrast with the corresponding plasmid harboring the $\mathrm{N}$-terminal sequence (Figure 3). Further deletion of the $\mathrm{N}$ terminus, which includes the WRKY domain, resulted in the restoration of some transactivation, suggesting that the WRKY domain has a suppression effect in the absence of the very N-terminal amino acids. However, deletion of the WRKY region did not increase the transcriptional activity of the rest of the proteins. On the contrary, transcription decreased. In a search of the OsWRKY31 protein sequence, we did not find the LxLxL motif, which is typically present in the suppression domains of Aux/IAA, WRKY proteins and ethylene response factors [35, 41, 42]. A possible explanation (at least in yeast) could be that the $\mathrm{N}$ terminus, which includes the WRKY domain, has a special conformation that affects the transactivation of OsWRKY31 and so any deletion of the sequence in this region would lead to a possible conformation change and a decrease or elimination of transcriptional activity in the rest of the protein.

The transcription of OsWRKY31 was induced in rice seedlings as early as $4 \mathrm{~h}$ post-treatment with the rice blast fungus $M$. grisea (Figure 4). This induction was much faster than that of a $P R$ gene, OsSci2. At this stage, $M$. grisea fungi were in the process of penetrating the epidermal cell layers of the rice leaves, suggesting that OsWRKY31 might be involved in early defense against the infection. In addition, overexpression of the OsWRKY31 gene significantly decreased lesion sizes and the number of infection sites of $M$. grisea fungi on transgenic rice plants (Figure 5A), indicating that pathogen invasion was blocked in the early stages as they spread. Constitutive expression of defense-related genes, such as $\mathrm{OsSci2}$ and $P B Z 1$, may contribute to the enhanced disease resistance of the OsWRKY31 overexpressor lines (Figure 5F) because their expressions were not induced by $M$. grisea in RNAi lines examined by RT-PCR (data not shown). In combination with the targeting of OsWRKY31-eGFP to the nucleus (Figure 2), the results indicate that OsWRKY31 may function as a transcription activator in the rice defense response.

Aux/IAAs encode the rapidly turned over transcriptional repressors of auxin-inducible genes [11]. Previous analyses of Arabidopsis mutants have revealed that gainof-function aux/iaa mutants have altered auxin sensitivity and pleiotropic defects in growth and development, including the reduction or increase in lateral root formation [43-47]. In OsWRKY31 transgenic plants, we noticed that lateral root formation and elongation were reduced (Figure 7). In addition, exogenous treatments with different types of auxins or auxin transport inhibitors indicated that the overexpressing plants are also less sensitive to high concentrations of auxin (Figure 7), results that are similar to those on the reported auxin-resistant mutants such as aux 1, axr1, axr2, axr4, axr5, axr6 and tir1 [13-15, 48]. In Arabidopsis, production of auxin-insensitive plants has been obtained by introducing gain-of-function aux/iaa mutants, which show typical auxin-insensitive phenotypes, such as fewer lateral roots, shorter hypocotyls and suppressed root inhibition with exogenous auxin at high concentrations $[49,50]$. We also found that the induction of OsWRKY31 was even faster than the expression of auxin-inducible OsIAA4 and $\mathrm{OsCrll}$ genes following treatment of rice seedlings with IBA (Figure 8B). The early auxin response of OsWRKY31 expression suggests that OsWRKY31 is a member of the early auxin response family. However, constitutive expression of auxin-inducible OsIAA4 and OsCrll genes in OsWRKY31 overexpressor lines did not exhibit corresponding phenotypes, such as more or longer lateral roots (Figure 8). An explanation for this dissimilarity may be that the constitutive expression in some of the rice $A u x / I A A$ genes, such as OsIAA4, might lead to the stabilization of these proteins at some specific stage or condition of development. In support of this idea, some SLR1/IAA14 overexpressing Arabidopsis plants exhibit an slr (solitary-root)1-like phenotype, which was interpreted by Fukaki et al. [47] to be the accumulation of IAA14 proteins in these $35 S:: I A A 14$ plants at the CaMV35S promoter, which is constitutively active in most plant tissues. Furthermore, even though rice $\mathrm{Crll}$ is a positive regulator of crown and lateral root formation, its expression has been found to be insufficient to initiate crown or lateral root development [16]. Nevertheless, further studies on the stability of rice IAA proteins in ectopic OsWRKY31-expressing plants are necessary to clarify this issue.

Auxin is known to negatively regulate several defense genes [51, 52], but some researches have demonstrated that in vitro IAA has some antimicrobial activity at relatively high concentrations [53, 54]. For example, potato meristems and young leaves are more resistant than old leaves to the late blight agent Phytophthora infestans, which is probably due to a relatively high level of auxins in these tissues that provide a natural defense against pathogenic spread and disease development [53]. Furthermore, IAA or other indole-related compounds can have a protective role against $M$. grisea infection in barley leaves [54]. In our study, overexpressing OsWRKY31 led to enhanced disease-resistance and auxin-related phenotypes in rice. Taking into account the known function of the SGT1b factor, this result indicates the existence of common components in certain aspects of the auxin signaling and defense response pathways [6-9]. Furthermore, we propose that OsWRKY31 might be such 
a component in this crosstalk between auxin and the defense signal transductions.

Functional redundancy is a common occurrence with structurally related transcription factors. For example, in Arabidopsis the structurally related WRKY18, WRKY40, WRKY60 and WRKY6 have been shown to have functional redundancy $[28,33]$. In this study, the RNAi lines of OsWRKY31 did not show opposite phenotypes to the overexpressing lines, implying the functional redundancy of this gene with its homologous member. Nevertheless, the identification of OsWRKY31 might help to elucidate the interlaced signaling pathways of the auxin response and disease resistance in rice.

\section{Materials and Methods}

\section{Isolation of OsWRKY31 and bioinformatics analysis}

The primers designed for OsWRKY31 amplification were based on public databases of the rice genome and expressed sequence tags. OsWRKY31 was amplified from a rice (cultivar IR 72) cDNA library induced by elicitors from $M$. grisea using LA Taq DNA polymerase (Takara, Dalian) with the primers 31BIF $5^{\prime}$-ttggatcct ttc tct ctg gaa aca atg tc-3' (BamHI site underlined) and 31R $5^{\prime}$-ttc att tac aaa aaa tgg aag aat ctg ata gaa cc-3'. The PCR product was cloned into a pUCm-T vector and sequenced from both ends.

A BLAST (Basic Local Alignment Search Tool) search of the National Center for Biotechnology Information (NCBI) database was used to carry out bioinformatic analysis. DNAMAN software (http://www.lynnon.com/download/index/html/) was applied to establish the primary structure, including nucleotide and amino-acid sequences. The ClustalW program with BOXSHADE (http://bioweb.pasteur.fr) was then used to align the protein sequences of the WRKY proteins.

\section{Subcellular localization of OsWRKY31}

A cDNA clone of OsWRKY31 was obtained through amplification with the primers of $31 \mathrm{BIF}$ and $31 \mathrm{XhR} 5^{\prime}$-tta ctcgag aaa atg gaa gaa tct gat aga acc-3' (XhoI site underlined). The PCR products were digested with the restriction enzymes BamHI and XhoI, and inserted in frame with $g f p$ at its $5^{\prime}$ end in pCaMV35S::eGFP ('e' stands for 'enhanced') linearized with BamHI and SalI. The constructed vector pCaMV35S::OsWRKY31-eGFP was confirmed by DNA sequencing.

The inner epidermis cells of onion (Allium cepa) were prepared for bombardment with pCaMV35S::OsWRKY31-eGFP or the pCaMV35S::eGFP plasmid on a PDS-1000/He system (Bio-Rad, USA) according to the manufacturer's instructions. After bombardment, the epidermises were cultured in the dark for $18 \mathrm{~h}$ at 28 ${ }^{\circ} \mathrm{C}$. GFP fluorescence was examined using confocal fluorescence microscopy (Olympus, Japan).

\section{A yeast one-hybrid assay}

In the transcription activation assay OsWRKY31 and a series of its deletion mutants were amplified by PCR and the products were inserted into the GAL4 DNA-binding domain of the pGBKT7 vector. The plasmids obtained were transformed into AH109 yeast cells according to protocols provided by Clontech (USA). The transformed yeast cells were streaked on selective SD-Trp and SDTrp-Ade-His medium plates to observe yeast growth at $30{ }^{\circ} \mathrm{C}$ for 3-4 days. An assay of $\beta$-galactosidase activity was performed using $O$-nitrophenyl $\beta$-D-galactopyranoside as a substrate.

The pBD-W31 plasmid for the OsWRKY31 encoding region was constructed from a PCR product amplified with primers of $31 \mathrm{EcoF}$ and $31 \mathrm{XhR}$ (Table 1). The plasmids of pBD-C1, pBD-C2 and $\mathrm{pBD}-\mathrm{C} 3$ contained fragments of $\mathrm{C} 1$ (aa 1-150, indicating the region of amino acids), C2 (aa 1-100) and C3 (aa 1-70), amplified using the primers $\mathrm{C} 1 \mathrm{R}, \mathrm{C} 2 \mathrm{R}$ and $\mathrm{C} 3 \mathrm{R}$, respectively, paired with 31 EcoF. Similarly, the plasmids of pBD-N1, pBD-N2 and pBD$\mathrm{dC} 1$ harbored fragments of N1 (aa 94-211), N2 (aa 37-211) and $\mathrm{dC} 1$ (aa 151-211), obtained using the primers N1F, N2F and dC1F, respectively, paired with $31 \mathrm{XhR}$. Fragments of N3 (aa 8-150), N4 (aa 16-150) and N5 (aa 28-150) were amplified using the primer C1R paired with the primers N3F, N4F and N5F, respectively, and were used to construct pBD-N3, pBD-N4 and pBD-N5 plasmids. The primers N1F and $\mathrm{C} 1 \mathrm{R}$ were applied to amplify the truncated N1C1 (aa 94-150) for pBD-N1C1. The plasmid pBD-WD, which does not contain the WRKY domain, was constructed using the product of the aa 1-37 fragment from primer pairs of 31EcoF and WDBamR, fused with the aa 94-211 fragment amplified by the primers of WDBamF and 31XhoR. Finally, the plasmid pBD-WC1 was obtained using an amplification product of $31 \mathrm{EcoF}$ and $31 \mathrm{C} 1$ from the pBD-WD plasmid.

\section{Plant materials and treatments}

Rice plants (Oryza sativa L. ssp. japonic cv. Zhonghua 17) were grown in a greenhouse at $28{ }^{\circ} \mathrm{C}$. To study abiotic stresses, 25 -day-old rice plants were sprayed with $100 \mu \mathrm{M}$ MeJA or nipped with a hemostat to cause wounding. To study pathogenic infection, 25-day-old rice seedlings were inoculated with conidiophores of the pathogen $M$. grisea (incompatible strain P131 and compatible strain MS220) at $10^{5}$ spores $/ \mathrm{ml}$ containing $0.01 \%$ (v/v) Tween-20. M. grisea cultures and conidiophore preparation were carried out according to the procedures described previously in Peng and Shishiyama [55]. The inoculated plants were kept in the dark for $24 \mathrm{~h}$ at $25{ }^{\circ} \mathrm{C}$ with $100 \%$ relative humidity and then moved to a normal culture environment. To serve as a control, seedlings

Table 1 Primers for $O s W R K Y 31$ cDNA amplification

\begin{tabular}{|c|c|c|}
\hline Primer & Sequence (restriction enzyme site) & \\
\hline $31 \mathrm{EcoF}$ & $5^{\prime}-\mathrm{ccg}$ aat tca tgt ctc ctg tgc cga gt- $3^{\prime}$ & EcoRI \\
\hline $\mathrm{N} 1 \mathrm{~F}$ & $5^{\prime}$-cag aat tca ata gtg ctt ttc ttc ctc tt- $3^{\prime}$ & EcoRI \\
\hline $\mathrm{N} 2 \mathrm{~F}$ & $5^{\prime}$-cag aat tcc agt gga gga agt acg gcg ag- $3^{\prime}$ & EcoRI \\
\hline $\mathrm{N} 3 \mathrm{~F}$ & $5^{\prime}-\mathrm{ccg}$ aat tcc atc aat cac acc atc tag gec at- $3^{\prime}$ & EcoRI \\
\hline $\mathrm{N} 4 \mathrm{~F}$ & $5^{\prime}-\operatorname{ccg}$ aat tcg get caa gga aag aga agc gca t-3' & EcoRI \\
\hline N5F & $5^{\prime}-\operatorname{ccg}$ aat tca cet ttg cgc cgc aca a-3' & EcoRI \\
\hline $\mathrm{dC} 1 \mathrm{~F}$ & $5^{\prime}-\operatorname{ccg}$ aat tcc ctc ttc cac ggc att-3' & EcoRI \\
\hline WDBamF & $5^{\prime}$-agg gat cca ata gtg ctt ttc ttc ctc tt- $3^{\prime}$ & BamHI \\
\hline WDBamR & $5^{\prime}-\operatorname{ttg}$ gat ccc tgg tgg ccg tcg ttg t-3' & BamHI \\
\hline $\mathrm{C} 1 \mathrm{R}$ & $5^{\prime}$-ctg gtc gac ctg att ctt gtt ctc tga agg t-3 & SalI \\
\hline $\mathrm{C} 2 \mathrm{R}$ & $5^{\prime}$-cta gtc gac aag agg aag aaa agc act-3' & SalI \\
\hline C3R & $5^{\prime}$-cta gtc gac ctt cgt tgc tgg gca att cat-3' & SalI \\
\hline
\end{tabular}


were treated with $0.01 \%$ Tween-20 and the leaves were sampled at designated time points before storage at $-80{ }^{\circ} \mathrm{C}$ for RNA isolation.

To evaluate the capacity of disease resistance, 3-week-old transgenic and control plants were inoculated with a strong virulent strain of $M$. grisea P140. Disease incidence was investigated 7 days post-inoculation. The lengths and numbers of lesions were averaged from at least five leaves from each line. For northern blot analysis, RNA was isolated from leaves $18 \mathrm{~h}$ post-inoculation.

\section{Analysis of RNA}

Total RNA was extracted using methods described in Chomczynski et al. [56]. RNA (20 $\mu \mathrm{g}$ for each sample) was separated in $1.2 \%$ agarose gels containing formaldehyde, and was transferred onto a Hybond $\mathrm{N}^{+}$nylon membrane and cross-linked using UV irradiation. The membrane was hybridized with a fragment of $O s$ WRKY31 or OsSci2 (a PR gene, GenBank acc. no. AY878694) using methods described in Guo et al. [30]. The hybridization signals were scanned using a phosphor screen (Amersham Pharmacia, UK).

For reverse transcriptase PCR (RT-PCR), total RNA was isolated from rice leaves cultured in a greenhouse for 25 days. Total RNA was treated with DNase I (RNase-free) and a ribonuclease inhibitor to remove any possible DNA contamination. The firststrand cDNA was synthesized using AMV transcriptase (TaKaRa, Dalian) in a $25-\mu \mathrm{l}$ reaction containing $2.5 \mu \mathrm{M}$ oligo (dT) primers and $2.5 \mu \mathrm{g}$ RNA according to the manufacturer's instructions. The synthesized cDNAs were used as a template for PCR amplification in a $25-\mu 1$ reaction mixture containing $1.5 \mu \mathrm{M} \mathrm{MgCl}_{2}, 200 \mu \mathrm{M}$ dNTP, $5 \%$ dimethyl sulfoxide, $2.5 \mathrm{U}$ of Taq DNA polymerase and $0.4 \mu \mathrm{M}$ gene-specific primers. The primers used were $5^{\prime}$-gga act ggt atg gtc aag gc- $3^{\prime}$ and $5^{\prime}$-agt ctc atg gat acc cgc ag-3' for Actin (AB047313) as an internal standard, $5^{\prime}$-agt get ttt ctt cet ctt agc c-3' and $5^{\prime}$-aat gea tcc tga cat tcg gtg-3' for OsWRKY31, 5' -acg cgt cca ctt tgc cca ag- $3^{\prime}$ and $5^{\prime}$-ttc tcc ggc gac agt gag ct- $3^{\prime}$ for PBZ1 (D38170), 5' -gag gaa ttc tgt gac cag aat gag-3' and 5'-gag act cga gag cta gac aca gc- $3^{\prime}$ for $O s S c i 2,5^{\prime}$-ggc att ccc ggt gec cat ga-3' and 5'-gtc cat cge cta tgg tgc gac-3' for OsIAA4 [16], and 5 '-agc aac gtg tcc aag ctg ct-3' and 5'-tgt agc cgc cgt acc cta at-3' for OsCrll (AB200234) [16].

\section{Generation of OsWRKY31 transgenic rice plants}

For overexpression, the fragment covering the encoding region of OsWRKY31 was cut from its ligated pUCm-T vector and inserted into the $\mathrm{pCoU}$ vector under the control of a maize ubiquitin promoter to generate pCo-Ubi::OsWRKY31. To suppress OsWRKY31 transcription, we constructed a hairpin structure as described by Wesley et al. [57]. A 260-bp (283-543 bp) OsWRKY31 fragment was used to generate the hairpin vector pCo-Ubi::OsWRKY31d after several digestions and ligations. The plasmids were confirmed through DNA sequencing and were transformed into rice calli (Zhonghua 17) using Agrobacterium-mediated transformation methods [58]. Rice calli were transformed with an empty vector as a control.

\section{Morphological analysis and hormone treatment of trans- genic plants}

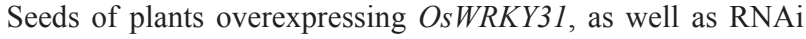
and control plants from the $\mathrm{T}_{2}$ generation, were grown on $1 / 2 \mathrm{MS}$ $\left(0.6 \%\right.$ agar, containing $30 \mathrm{mg} / 1$ hygromycin) at $26{ }^{\circ} \mathrm{C}$ in a plant growth chamber. Morphological data, including plant height, seminal root length, adventitious root length, lateral root length, the number of adventitious roots and the number of lateral roots, were measured using 7-day-old rice seedlings [18]. Statistics from at least 15 plants from each transgenic line were taken.

To investigate the effects of exogenous auxin on root elongation and development, control and transgenic seeds were sown in black cups with an agar medium for 4 days and then transferred to media containing different concentrations of IBA, 2,4-D and NAA. The hormone solutions were changed every day and the lengths of the 20 longest lateral roots were measured after 6 days of treatment. To inhibit auxin transport, seeds were sown on $1 / 2$ MS with or without $1 \mu \mathrm{M}$ 2,3,5-triiodobenzoic acid (TIBA). The lengths of the lateral roots were measured 6 days after the treatment. For mRNA analyses, 4-day-old seedlings were treated with IBA $(1 \mu \mathrm{M}), 1$-NAA $(1 \mu \mathrm{M})$, or 2 -NAA $(1 \mu \mathrm{M})$, and the roots were sampled at designated time points.

\section{Acknowledgments}

This research was supported by the National Basic Research Program of China (2006CB101905) and the National Nature Science Foundation of China (30370139 and 30471122).

\section{References}

1 Hammond-Kosack KE, Jones JD. Resistance gene-dependent plant defense responses. Plant Cell 1996; 8:1773-1791.

2 Yang Y, Shah J, Klessiq DF. Signal perception and transduction in plant defense responses. Gene Dev 1997; 11:1621-1639.

3 Lorrain S, Vailleau F, Balague C, Roby D. Lesion mimic mutants: keys for deciphering cell death and defense pathways in plants? Trends Plant Sci 2003; 8:263-271.

4 Heil M. Ecological costs of induced resistance. Curr Opin Plant Biol 2002; 5:345-350.

5 Brown JKM. A cost of disease resistance: paradigm or peculiarity? Trends Genet 2003; 19:667-671.

6 Austin MJ, Muskett P, Kahn K, Feys BJ, Jones JD, Parker JE. Regulatory role of $S G T 1$ in early $R$ gene-mediated plant defenses. Science 2002; 295:2077-2080.

7 Azevedo C, Sadanandom A, Kitagawa K, Freialdenhoven A, Shirasu K, Schulze-Lefert P. The RAR1 interactor SGT1, an essential component of $R$ gene-triggered disease resistance. Science 2002; 295:2073-2076.

8 Gray WM, Muskett PR, Chuang HW, Parker JE. Arabidopsis $\mathrm{SGT} 1 \mathrm{~b}$ is required for $\mathrm{SCF}^{\mathrm{TIR} 1}$-mediated auxin response. Plant Cell 2003; 15:1310-1319.

9 Peart JR, Lu R, Sadanandom A, et al. Ubiqutin ligaseassociated protein SGT1 is required for host and nonhost disease resistance in plants. Proc Natl Acad Sci USA 2002; 99:10865-10869.

10 Navarro L, Dunoyer P, Jay F, et al. A plant miRNA contributes to antibacterial resistance by repressing auxin signaling. Science 2006; 312:436-439.

11 Leyser O. Dynamic integration of auxin transport and signaling. Curr Biol 2006; 16:R424-R433.

12 Reed JW. Roles and activities of Aux/IAA proteins in Arabi- 
dopsis. Trends Plant Sci 2001; 6:420-425.

13 Ulmasov T, Hagen G, Guilfoyle TJ. ARF1, a transcription factor that binds to auxin response elements. Science 1997; 276:1865-1868.

14 Hobbie L, Estelle M. The axr4 auxin-resistant mutants of Arabidopsis thaliana define a gene important for root gravitropism and lateral root initiation. Plant $J$ 1995; 7:211-220.

15 Bennett MJ, Marchant A, Green HG, et al. Arabidopsis AUXI gene: a permiase-like regulator of root gravitropism. Science 1996; 273:948-950.

16 Inukai Y, Sakamoto T, Ueguchi-Tanaka M, et al. Crown rootless 1, which is essential for crown root formation in rice, is a target of an AUXIN RESPONSE FACTOR in auxin signaling. Plant Cell 2005; 17:1387-1396.

17 Hao ZB, Ichii M. A mutant RM109 of rice (Oryza sativa L.) exhibiting altered lateral root initiation and gravitropism, Jpn J Crop Sci 1999; 68:245-252.

18 Debi BR, Mushika J, Taketa S, Miyao A, Hirochika H, Ichii M. Isolation and characterization of a short lateral root mutant in rice (Oryza sativa L.). Plant Sci 2003; 165:895-903.

19 Nemhauser JL, Feldman LF, Zambryski PC. Auxin and ETTIN in Arabidopsis gynoecium morphogenesis. Development 2000; 127:3877-3888.

20 Hardtke CS, Berleth T. The Arabidopsis gene MONOPTEROS encodes a transcription factor mediating embryo axis formation and vascular development. EMBO J 1998; 17:1405-1411.

21 Liscum E, Briggs WR. Mutations in the NPH1 locus of Arabidopsis disrupt the perception of phototropic stimuli. Plant Cell 1995; 7:473-485.

22 Tian CE, Muto H, Higuchi K, et al. Disruption and overexpression of auxin response factor 8 gene of Arabidopsis affect hypocotyl elongation and root growth habit, indicating its possible involvement in auxin homeostasis in light condition. Plant J 2004; 40:333-343.

23 Staswick PE, Tiryaki I, Rowe ML. Jasmonate response locus, JAR1 and several related Arabidopsis genes encode enzymes of the firefly luciferase superfamily that show activity on jasmonic, salicylic, and indole-3-acetic acids in an assay for adenylation. Plant Cell 2002; 14:1405-1415.

24 Chen $\mathrm{C}$, Chen Z. Isolation and characterization of two pathogen- and salicylic acid-induced genes encoding WRKY DNA-binding proteins from tobacco. Plant Mol Biol 2000; 42:387-396.

25 Cormack RS, Eulgem T, Rushton PJ, Kochner P, Hahlbrock K, Somssich IE. Leucine zipper-containing WRKY proteins widen the spectrum of immediate early elicitor-induced WRKY transcription factors in parsley. Biochim Biophys Acta 2002; 1576:92-100.

26 Dong J, Chen C, Chen Z. Expression profiles of the Arabidopsis WRKY gene super family during plant defense response. Plant Mol Biol 2003; 51:21-37.

27 Turck F, Zhou A, Somssich IE. Stimulus-dependent, promoterspecific binding of transcription factor WRKY1 to its native promoter and the defense-related gene PCPR1-1 in Parsley. Plant Cell 2004; 16:2573-2585.

$28 \mathrm{Xu}$ X, Chen C, Fan B, Chen Z. Physical and functional interactions between pathogen-induced Arabidopsis WRKY18, WRKY40, and WRKY60 transcription factors. Plant Cell 2006; 18:1310-1326.
29 Ryu HS, Han M, Lee SK, et al. A comprehensive expression analysis of the $W R K Y$ gene superfamily in rice plants during defense response. Plant Cell Rep 2006; 25:836-847.

30 Guo ZJ, Kan YC, Chen XJ, Li DB, Wang DW. Characterization a rice $W R K Y$ gene whose expression is induced upon pathogen attack and mechanical wounding. Acta Bot Sin 2004; 46:955-964.

31 Wang HH, Hao ZN, Xie K, Wu KL, Guo ZJ. Leucine zipper like structure in rice WRKY89 enhances its affinity for binding with W box elements. Chinese Sci Bull 2005; 50:980-989.

32 Liu XQ, Bai XQ, Qian Q, Wang XJ, Chen MS, Chu CC. OsWRKY03, a rice transcriptional activator that functions in defense signaling pathway upstream of OsNPR1. Cell Res 2005; 15:593-603.

33 Robatzek S, Somssich IE. Targets of AtWRKY6 regulation during plant senescence and pathogen defense. Genes Dev 2002; 16:1139-1149.

34 Sun C, Palmqvist S, Olsson H, Borén M, Ahlandsberg S, Jansson C. A novel WRKY transcription factor, SUSIBA 2, participates in sugar signaling in barley by binding to the sugarresponsive elements of the iso1 promoter. Plant Cell 2003; 15:2076-2092.

35 Xie Z, Zhang ZL, Zou X, et al. Annotations and functional analyses of the rice $W R K Y$ gene superfamily reveal positive and negative regulators of abscisic acid signaling in aleurone cells. Plant Physiol 2005; 137:176-189.

36 Xie Z, Zhang ZL, Zou X, Yang G, Komatsu S, Shen QJ. Interactions of two abscisic-acid induced WRKY genes in repressing gibberellin signaling in aleurone cells. Plant $J$ 2006; 46:231-242.

37 Johnson CS, Kolevski B, Smyth DR. TRANSPARENT TESTA GLABRA2, a trichome and seed coat development gene of Arabidopsis, encodes a WRKY transcription factor. Plant Cell 2002; 14:1359-1375.

38 Devaiah BN, Karthikeyan AS, Raghothama KG. WRKY75 transcription factor is a modulator of phosphate acquisition and root development in Arabidopsis. Plant Physiol 2007; 143:1789-1801.

39 Eulgem T, Rushton PJ, Robatzek S, Somssich IE. The WRKY superfamily of plant transcription factors. Trends Plant Sci 2000; 5:199-206.

40 Wu KL, Guo ZJ, Wang HH, Li J. The WRKY family of transcription factors in rice and Arabidopsis and their origins. DNA Res 2005; 12:9-26.

41 Ohta M, Matsui K, Hiratsu K, Shinshi H, Ohme-Takagi M. Repression domains of class II ERF transcriptional repressors share an essential motif for active repression. Plant Cell 2001; 13:1959-1968.

42 Tiwari SB, Hagen G, Guilfoyle TJ. AUX/IAA proteins contain a potent transcriptional repression domain. Plant Cell 2004; 16:533-543.

43 Leyser HM, Pickett FB, Dharmasiri S, Estelle M. Mutations in the $A X R 3$ gene of Arabidopsis result in altered auxin response including ectopic expression from the $S A U R-A C 1$ promoter. Plant J 1996; 10:403-413.

44 Tian Q, Reed JW. Control of auxin-regulated root development by the Arabidopsis thaliana SHY2/IAA3 gene. Development 1999; 126:711-721.

45 Nagpal P, Walker LM, Young JC, et al. AXR2 encodes a 
member of the Aux/IAA protein family. Plant Physiol 2000; 123:563-574.

46 Rogg LE, Lasswell J, Bartel B. A gain-of-function mutation in IAA28 suppresses lateral root development. Plant Cell 2001; 13:465-480.

47 Fukaki H, Tameda S, Masuda H, Tasaka M. Lateral root formation is blocked by a gain-of-function mutation in the SOLITARY-ROOT/IAA14 gene of Arabidopsis. Plant J 2002; 29:153-168.

48 Timpte C, Lincoln C, Pickett FB, Turner J, Estelle M. The $A X R 1$ and $A U X 1$ genes of Arabidopsis function in separate auxin-response pathways. Plant $J$ 1995; 8:561-569.

49 Park JY, Kim HJ, Kim J. Mutation in domain II of IAA1 confers diverse auxin-related phenotypes and represses auxinactivated expression of $A u x / I A A$ genes in steroid regulatorinducible system. Plant $J$ 2002; 32:669-683.

50 Nakamura A, Umemura I, Gomi K, et al. Production and characterization of auxin-insensitive rice by overexpression of a mutagenized rice IAA protein. Plant J 2006; 46:297-306.

51 Grosset J, Meyer Y, Chartier Y, Kauffmann S, Legrand M, Fritig B. Tobacco mesophyll protoplasts synthesize 1,3-betaglucanase, chitinases, and "osmotins" during in vitro culture. Plant Physiol 1990; 92:520-527.

52 Jouanneau JP, Lapous D, Guern J. In plant protoplasts, the spontaneous expression of defense reactions and the responsiveness to exogenous elicitors are under auxin control. Plant Physiol 1991; 96:459-466.

53 Martinez-Noël GMA, Madrid EA, Bottini R, Lamattina L. Indole acetic acid attenuates disease severity in potato-Phytophthora infestans interaction and inhibits the pathogen growth in vitro. Plant Physiol Biochem 2001; 39:815-823.

54 Ueno M, Kihara J, Honda Y, Arase S. Indole-related compounds induce the resistance to rice blast fungus, Magnaporthe grisea in barley. J Phytopathol 2004; 152:606-612.

55 Peng YL, Shishiyama J. Temporal sequence of cytological events in rice leaves affected with Pyricularia oryzae. Can J Bot 1988; 66:730-735.

56 Chomczynski P, Sacchi N. Single-step method of RNA isolation by acid guanidinium thiocyanate-phenol-chlorform extraction. Anal Biochem. 1987; 162:156-159.

57 Wesley SV, Helliwell CA, Smith NA, et al. Construct design for efficient, effective and high-throughput gene silencing in plants. Plant J 2001; 27:581-590.

58 Hiei Y, Ohta S, Komari T, Kumashiro T. Efficient transformation of rice (Oryza sativa L.) mediated by Agrobacterium and sequence analysis of boundaries of the T-DNA. Plant J 1994; 6:271-282. 